\title{
Stabilization of Tropical Peat by Chemical Grout.
}

\begin{abstract}
Peats have low shear strength and high deformation characteristics. Cement, sometimes with other industrial binders, is widely used for the stabilization of peats by deep mixing. However, peats lack a favorable structure for the chemical reactions, coupled with high moisture content that is acidic in nature. So, the efficiency of the binders is low making it an expensive option. This paper presents the effectiveness of using calcium chloride and kaolinite in cement-sodium silicate grout for improving the strength of tropical peat. The change in shear strength of the treated samples was evaluated by the vane shear test and moisture content test. The microstructural changes were evaluated by scanning electron microscopy and energy dispersive $\mathrm{x}$-ray spectrometer analysis. Calcium chloride seemed to have different effects on the shear strength of peat and was observed to play an important role in the effectiveness of the chemical stabilizers. Experimental results showed that kaolinite (more than 10\%) has a crucial rule in increasing the shear strength of peat. It was observed that sodium silicate within $3 \%$ and cement has favorable effect on the shear strength of peat and induce a decrease in the moisture content of mixtures consisting of peat and themselves and also lead to some favorable changes in the microstructure.
\end{abstract}

Keyword: Cement-sodium silicate grout; Kaolinite; Peat; Soil stabilization 